\title{
BMJ open Mathematical modelling to restore circulating IGF-1 concentrations in children with Crohn's disease-induced growth failure: a pharmacokinetic study
}

\author{
A Rao, ${ }^{1}$ J F Standing, ${ }^{2}$ S Naik, ${ }^{1}$ M O Savage, ${ }^{3}$ I R Sanderson ${ }^{1}$
}

To cite: Rao A, Standing JF, Naik S, et al. Mathematical modelling to restore circulating IGF-1 concentrations in children with Crohn's disease-induced growth failure: a pharmacokinetic study. BMJ Open 2013;3:e002737. doi:10.1136/bmjopen-2013002737

- Prepublication history for this paper are available online. To view these files please visit the journal online (http://dx.doi.org/10.1136/ bmjopen-2013-002737).

Received 16 February 2013 Revised 28 April 2013 Accepted 29 April 2013

This final article is available for use under the terms of the Creative Commons Attribution Non-Commercial 2.0 Licence; see http://bmjopen.bmj.com

For numbered affiliations see end of article.

\section{Correspondence to}

Professor lan Sanderson;

i.r.sanderson@qmul.ac.uk

\section{ABSTRACT}

Objectives: Children with Crohn's disease grow poorly, and inflammation depresses the response of insulin-like growth factor-1 (IGF-1) to growth hormone. Correcting the inflammation normalises growth velocity; however, removing inflammation cannot be achieved in all children. Our lack of understanding of IGF-1 kinetics has hampered its use, particularly as high IGF-1 concentrations over long periods may predispose to colon cancer. We hypothesised that mathematical modelling of IGF-1 would define dosing regimes that return IGF-1 concentrations into the normal range, without reaching values that risk cancer. Design: Pharmacokinetic intervention study.

Setting: Tertiary paediatric gastroenterology unit. Participants: 8 children (M:F; 4:4) entered the study. All completed: 5 South Asian British; 2 White British; 1 African British. Inclusion criteria: Children over 10 years with active Crohn's disease ( $C$ reactive protein $>10 \mathrm{mg} / \mathrm{l}$ or erythrocyte sedimentation rate $>25 \mathrm{~mm} / \mathrm{h}$ ) and height velocity $<-2$ SD score. Exclusion criteria: closed epiphyses; corticosteroids within 3 months; neoplasia or known hypersensitivity to recombinant human IGF-1 (rhIGF-1).

Interventions: Subcutaneous rhlGF-1 $(120 \mu \mathrm{g} / \mathrm{kg})$ per dose over two admissions: the first as a single dose and the second as twice daily doses over 5 days.

Primary outcome: Significant increase in circulating IGF-1.

Secondary outcomes: Incidence of side effects of IGF-1. A mathematical model of circulating IGF-1 $\left(A_{c}\right)$ was developed to include parameters of endogenous synthesis $\left(K_{\text {syn }}\right)$; exogenous uptake $\left(K_{a}\right)$ from the subcutaneous dose $\left(A_{s}\right)$ : and IGF-1 clearance: where $d A_{c} / d t=K_{\text {syn }}-K_{\text {out }} \times A_{c}+K_{a} \times A_{S}$.

Results: Subcutaneous IGF-1 increased concentrations, which were maintained on twice daily doses. In covariate analysis, disease activity reduced $K_{\text {syn }}(p<0.001)$. Optimal dosing was derived from least squares regression fitted to a dataset of 384 Crohn's patients, with model parameters assigned by simulation.

Conclusions: By using age, weight and disease activity scaling in IGF-1 dosing, over $95 \%$ of children will have normalised IGF-1 concentrations below +2.5 SDs of the normal population mean, a level not associated with cancer risk.

\section{ARTICLE SUMMARY}

Article focus

- One-third of the children with Crohn's disease have growth retardation.

- Children with active inflammation have insensitivity to growth hormone, resulting in low circulating insulin-like growth factor-1 (IGF-1).

- There is no agreed growth therapy for children whose inflammation is intractable to treatment, because very high and sustained IGF- 1 concentrations are a risk factor for colon cancer in adults with acromegaly.

Key messages

- IGF-1 can be restored to the normal range by subcutaneous injections.

- The endogenous synthesis of IGF-1 depends on Crohn's disease activity variations in both determine the circulating IGF-1 concentrations.

- A new mathematical model which incorporates disease activity (in addition to weight and age) will allow paediatric gastroenterologists to calculate doses that keep the circulating IGF-1 in the upper normal range.

Strengths and limitations of this study

- Using the mathematical model, IGF-1 can be prescribed in doses that do not increase the risk of cancer.

- For the first time, long-term IGF-1 treatment can be studied in children to determine if it enhances growth and this is a critical step in offering a therapy (much demanded by patients) for growth retardation in children with Crohn's disease.

- A limitation of the study is that long-term studies over several years will still be required on a large group of children.

\section{INTRODUCTION}

A quarter of cases of Crohn's disease now present in children and adolescents under 18 years $^{12}$ and its incidence in childhood is increasing. ${ }^{3}$ Around one third of the children experience linear growth retardation, 
caused in part by undernutrition and in part by the direct effects of inflammation on growth. ${ }^{4}$

Growth in childhood is regulated by growth hormone $(\mathrm{GH})$, secreted from the pituitary, which stimulates the production of insulin-like growth factor-1 (IGF-1) by the liver and growth plates of bones. ${ }^{5}$ Children with active Crohn's disease have low circulating IGF-1 and increased circulating cytokines. ${ }^{6}{ }^{7}$ Treatment of the inflammation, for example, by an enteral diet, results in a reduction in cytokines like IL- 6 and an increase in IGF-1 within 3 days. ${ }^{7}$ Thus, the optimum treatment for improving growth is to eliminate the inflammation. Nevertheless, some children's inflammation remains intractable to treatment despite the best efforts of clinicians. For this group, there is currently no agreed therapy to enhance growth.

Rats with TNBS-induced colonic inflammation grow poorly ${ }^{8}$; this is also associated with increased cytokines IL-6 and TNF and a low circulating IGF-1. ${ }^{9}$ Exogenous IGF-1 given to the rats with colitis enhanced their growth. ${ }^{8}$ In transgenic mice, without inflammation, high levels of circulating IL-6, generated by a widely acting promoter, depressed both IGF-1 and growth. ${ }^{10}$ Thus, the link between inflammatory cytokines, IGF-1 and poor growth is strong. ${ }^{11}$ There is a functional insensitivity to GH in children with Crohn's disease. Recombinant IGF-1 is now a recognised therapy for children with GH insensitivity syndrome (GHIS) due to genetic defects of the GH receptor or IGF-1 gene ${ }^{12}$; we therefore hypothesised that IGF-1 concentrations in children with active Crohn's disease and poor linear growth could be restored by administering rhIGF-1.

Restoring IGF-1 in children with Crohn's disease who may have some endogenous production is not straightforward, because high levels of IGF-1 may be harmful. For rhIGF-1 to be therapeutically useful, its circulating levels over the long term should be returned to normal values by replacement, and not given in excess. Patients with acromegaly who have very high concentrations of GH and IGF-1, maintained over decades, have a doubling in the incidence of colon cancer. ${ }^{13}$ This could, in theory, be compounded in children with Crohn's disease, as inflammation is also a risk factor for intestinal cancer.

A mathematical model for administration of rhIGF-1, based on detailed pharmacokinetics would resolve these difficulties, as dosing could be tailored to achieve circulating concentrations that remain within the normal range. We therefore undertook a careful study of subcutaneous rhIGF-1 administration in children with Crohn's disease-induced growth retardation. We developed a model which used physiological parameterisation, disease activity to predict endogenous IGF-1 synthesis and body weight to scale the volume of distribution. Parameters of protein loss, such as protein-losing enteropathy, were also considered. The model was used to recommend dosing which allows children to be treated with rhIGF-1 without its concentration rising above the normal range.
METHODS

\section{Patient selection}

Following ethical approval from the East London \& City Research Ethics Committee (reference number $07 / \mathrm{H} 0705 / 77)$ and regulatory approval from the UK Medicines and Healthcare products Regulatory Agency (Eudract number: 2007-004269-16), written informed consent was obtained from the parents and patients attending the paediatric inflammatory bowel disease clinic at Barts and The London Hospital for Children. Inclusion criteria were age $\geq 10$ years; known Crohn's disease diagnosed by endoscopic, histological and radiological methods; ${ }^{14}$ a height velocity measured over at least a 6 -month period of $<-2$ SD Score (SDS) according to the patient's age and gender; and an evidence of active inflammation as demonstrated by either an erythrocyte sedimentation rate $(\mathrm{ESR})>25 \mathrm{~mm} / \mathrm{h}$ and/or a $\mathrm{C}$ reactive protein $(\mathrm{CRP})>10 \mathrm{mg} / \mathrm{l}$. Exclusion criteria were corticosteroid use in the preceding 3 months; active or suspected neoplasia; known hypersensitivity to exogenous rhIGF-1 (Increlex, Ipsen UK); and the presence of closed epiphyses.

All patients had a full history and physical examination, including an accurate recording of height, weight and assessment of pubertal status. In addition, they also had an ECG and faecal $\alpha 1$-antitrypsin levels (g/l) measured.

\section{Study design}

Exogenous rhIGF-1 was administered by subcutaneous injection at doses of $120 \mu \mathrm{g} / \mathrm{kg}$ over two admissions. Admission 1 investigated the effects of a single dose of rhIGF-1 over a $24 \mathrm{~h}$ inpatient stay. Baseline blood screens included full blood count (FBC), electrolytes, inflammatory markers (CRP and ESR), baseline IGF-1, IGFBP-3, acid labile subunit (ALS) and blood sugar. The Pediatric Crohn's Disease Activity Index (PCDAI) was calculated..$^{15} 16$

Each patient was then given a single subcutaneous injection of rhIGF-1 at a dose of $120 \mu \mathrm{g} / \mathrm{kg}$. Serial venous blood samples were drawn at the following time points: $0,1,2,3,4,6,12,17$ and $24 \mathrm{~h}$. Blood sugars and vital signs were checked regularly. Children ate and drank freely, and continued to receive their prescribed, non-corticosteroid treatment for Crohn's disease.

Following a wash out of at least 3 months, the participants were readmitted for admission 2 , investigating the effects of repeated doses of rhIGF-1. On this occasion, six doses of rhIGF-1 were administered over a 5-day trial period, with doses given at $0,12,72,84,96$ and $108 \mathrm{~h}$. The injection sites were rotated according to the patient's wishes. Serial blood samples for further IGF-1, IGFBP-3, ALS and blood sugar were collected during the 5 days at $0,1,2,3,4,6,12,17,24,48,72,96$ and $120 \mathrm{~h}$. Additional samples were also taken for clinical reasons when there was a possibility of hypoglycaemia. If sufficient sample was collected, IGF-1 levels were also measured. In addition, vital signs, FBC, electrolytes and inflammatory markers were measured daily. Patients 
were kept as inpatients during the days that the rhIGF-1 was administered, but were allowed home during the 2 days in which they received no injections. Patients were discharged home on day 6.

\section{Assays and samples}

All samples were stored at $-20^{\circ} \mathrm{C}$ until analysis. Plasma glucose was determined immediately after blood sampling (Beckman Instruments, Palo Alto, California, USA).

\section{IGF-1 and IGFBP-3}

IGF-1 and IGFBP-3 levels were measured by competitive binding radioimmunoassay (Esoterix Inc Laboratory Services). The sensitivity of the assay for IGF-1 was $15 \mathrm{ng} / \mathrm{ml}$ and the intra-assay coefficient of variation averaged $14.1 \%$. The sensitivity of the assay for IGFBP-3 was $0.3 \mathrm{mg} / 1$ and the intra-assay coefficient of variation averaged $13 \%$.

\section{Acid labile subunit}

ALS levels were measured by radioimmunoassay (ALS-RIA) using purified human ALS as tracer. The intra-assay coefficient of variation ranged from $8 \%$ to $17.4 \%$.

\section{Mathematical model development}

Measured IGF-1 concentrations were fitted for all individuals simultaneously using the non-linear mixed effects modelling software NONMEM V.7.1. ${ }^{17}$ Model building was undertaken using the first-order conditional estimation method with interaction. A turnover model was used according to the following differential equations:

$$
\begin{gathered}
\frac{\mathrm{dA}_{\mathrm{c}}}{\mathrm{dt}}=\mathrm{K}_{\mathrm{syn}}-\mathrm{K}_{\text {out }} \times \mathrm{A}_{\mathrm{c}}+\mathrm{K}_{\mathrm{a}} \times \mathrm{A}_{\mathrm{s}} \\
\frac{\mathrm{dA}_{\mathrm{s}}}{\mathrm{dt}}=-\mathrm{K}_{\mathrm{a}} \times \mathrm{A}_{\mathrm{s}}
\end{gathered}
$$

where $A_{c}$ is the amount of circulating IGF-1 at time $t ; A_{s}$ the amount in the subcutaneous tissue following a dose, with initial conditions adjusted each time a dose is administered; $\mathrm{K}_{\text {syn }}$ a zero order production rate of endogenous IGF-1 in $\mu \mathrm{g} / \mathrm{h} ; \mathrm{K}_{\text {out }}$ a first-order elimination rate constant in $\mathrm{h}^{-1}$; and $\mathrm{K}_{\mathrm{a}}$ a first order absorption rate constant describing exogenous IGF-1 appearance following a subcutaneous dose in $\mathrm{h}^{-1}$. At steady state prior to exogenous dose, circulating IGF-1 is given by the ratio of $\mathrm{K}_{\text {syn }}$ to $\mathrm{K}_{\text {out }}$.

In addition to $\mathrm{K}_{\mathrm{syn}}$ and $\mathrm{K}_{\mathrm{a}}$, the fixed effect parameters IGF-1 clearance $\left(\mathrm{C}_{\mathrm{L}}\right)$ in $\mathrm{l} / \mathrm{h}$ and distribution volume $\left(V_{D}\right)$ in litre were estimated, $K_{\text {out }}$ being given by the ratio of $\mathrm{C}_{\mathrm{L}}$ to $\mathrm{V}_{\mathrm{D}}$. Variability was tested for all parameters between the participants and residual variability was described using a heteroscedastic model. Allometric weight scaling was applied to $\mathrm{C}_{\mathrm{L}}$ and $\mathrm{V}_{\mathrm{D}}$ a priori using linear scaling for $\mathrm{V}_{\mathrm{D}}$ and weight raised to the power 0.75 for $\mathrm{C}_{\mathrm{L}}{ }^{18} \mathrm{~K}_{\mathrm{syn}}$ was further scaled with linear weight. Tested covariates were CRP, ESR, PCDAI score and age.
Model development used the NONMEM objective function value $(\mathrm{OFV})$; parameter estimate precision was derived through a non-parametric bootstrap ${ }^{19}$ and graphical assessment of basic goodness-of-fit plots and model simulations was undertaken. The OFV is proportional to -2 times the log-likelihood of the data given the parameter estimates, and a decrease in OFV of 3.84 with 1 degree of freedom gives a significantly improved fit with a probability $\mathrm{p}<0.05$. A utility function based on the final model was used to predict the average concentration $\left(\mathrm{C}_{\text {ave }}\right)$ with a dosing regimen derived from the integral of the IGF-1 against the time curve divided by time. Maximum utility was defined as $\mathrm{C}_{\mathrm{ave}}$ of $+0.50 \mathrm{SDS}$ with linear penalty for deviations above and below this target. The dose was optimisied to give a model-derived steady-state $\mathrm{C}_{\text {ave }}$ by the following model:

$$
\text { Target }=\operatorname{SDS}_{\mathrm{i}}+\varepsilon_{\mathrm{i}}
$$

$$
\text { Utility }=\sum_{\mathrm{i}=1}^{\mathrm{n}}\left(\operatorname{target}-\mathrm{SDS}_{\mathrm{i}}\right)^{2}
$$

where target is the SDS aim (in this case +0.50 ); $\mathrm{SDS}_{\mathrm{i}}$ is the individual predicted SDS derived from model predicted $\mathrm{C}_{\mathrm{AVE}}$; and $\varepsilon_{\mathrm{i}}$ denotes the individual deviations from the target. Utility is minimised $\varepsilon_{\mathrm{i}}$ by least squares regression.

Demographic details for 384 children aged 8-14 years from the clinical database were each assigned a random PCDAI score (from a uniform distribution 0-48) and also individual model parameters. The utility function was maximised with either fixed dosing, dosing based on weight, weight and age, or weight, age and PCDAI score. Differences in concentrations were explored with 12 and 24 hourly dosing regimens.

\section{Calculation of sample size}

The size was derived from the number of children needed to show a significant increase in IGF-1, based on the increases in IGF-1 seen in a cohort of children with treated with IGF-1 for GHIS. This showed that in 18 children, the concentration before drug was $330 \mathrm{ng} / \mathrm{ml}$ (SEM $20 \mathrm{ng} / \mathrm{ml}$ ) and the concentration after $4 \mathrm{~h}$ was $535 \mathrm{ng} / \mathrm{ml}$ (SEM $20 \mathrm{ng} / \mathrm{ml}$ ). Therefore, to detect a difference in concentration of 205 (535-330) before drug and after $4 \mathrm{~h}$ and SD of 84.85 (calculated from SE of the Mean of 20 with sample size of 18 ), with $80 \%$ power at the $5 \%$ level of significance, four patients are required.

\section{RESULTS}

\section{rhIGF-1 therapy in children with Crohn's disease}

Children with active Crohn's disease and whose growth was inhibited were recruited into the study (table 1). Impairment of height velocity is characteristic of many children with active Crohn's disease, ${ }^{420-22}$ and all eight participants recruited in the study (median age 12.97) had a height velocity that was more than 2 SDs below 
Table 1 Patient characteristics at recruitment into the trial

\begin{tabular}{|c|c|c|c|c|c|c|c|c|}
\hline & \multicolumn{8}{|l|}{ Patients } \\
\hline & LN01 & LN02 & LN03 & LN04 & LN05 & LN06 & LN07 & LN08 \\
\hline Gender & $\mathrm{F}$ & $\mathrm{F}$ & M & M & $\mathrm{F}$ & $\mathrm{F}$ & M & M \\
\hline Age & 13.11 & 11.5 & 14.23 & 10.67 & 14.82 & 12.7 & 12.82 & 14.66 \\
\hline Ethnicity & Caucasian & Asian & Asian & Asian & Asian & Asian & African & Caucasian \\
\hline Tanner stage & P1 B1 & P1 B1 & P3 G3 & P1 G1 & P2 B2 & P2 B2 & P2 G2 & P1 G1 \\
\hline HV SDS at recruitment & -2.11 & -2.11 & -4.18 & -2.83 & -2.27 & -3.87 & -4.43 & -4.88 \\
\hline HV SDS at time of trial & -2.11 & -2.14 & -1.84 & 0.36 & 1.69 & 3.55 & -4.43 & -4.88 \\
\hline PCDAI & 12.5 & 20 & 17.5 & 10 & 47.5 & 15 & 12.5 & 10 \\
\hline Medication & 5-ASA & 5-ASA & $\begin{array}{c}\text { 5-ASA } \\
\text { AZA } \\
\text { IFX }\end{array}$ & $\begin{array}{l}\text { 5-ASA } \\
\text { AZA } \\
\text { Adalum }\end{array}$ & $\begin{array}{l}\text { 5-ASA } \\
\text { AZA } \\
\text { Adalum }\end{array}$ & $\begin{array}{c}\text { 5-ASA } \\
\text { AZA } \\
\text { IFX }\end{array}$ & $\begin{array}{l}\text { 5-ASA } \\
\text { AZA }\end{array}$ & 5-ASA \\
\hline $\begin{array}{l}\text { Faecal A1AT }(\mathrm{g} / \mathrm{l}) \\
\text { Montreal classification }\end{array}$ & 3.34 & 0.82 & 0.88 & 0.49 & 2.63 & 2.28 & 0.08 & 0.45 \\
\hline Disease location & L1 & L2 & L3 & L3 & L1 & L3 & L1 & L1 \\
\hline Behaviour & B1 & B1 & B3 & B3 & B2 & B1 & B2 & B1 \\
\hline Upper & $\mathrm{N}$ & $\mathrm{N}$ & $Y$ & $\mathrm{~N}$ & $\mathrm{Y}$ & $\mathrm{Y}$ & $\mathrm{N}$ & $\mathrm{N}$ \\
\hline Perianal & $\mathrm{N}$ & $\mathrm{N}$ & $\mathrm{Y}$ & $\mathrm{Y}$ & $\mathrm{N}$ & $\mathrm{N}$ & $\mathrm{N}$ & $\mathrm{N}$ \\
\hline
\end{tabular}

Tanner stage: P, pubic hair; B, breast stage; G, genitalia. Medications: 5-ASA, 5-aminosalicylic acid; AZA, azathioprine; IFX, infliximab; Adalum, adalumimab. Montreal classification: L1, ileal; L2, colonic; L3, ileocolonic; B1, non-stricturing, non-penetrating; B2, stricturing; B3, penetrating.

PCDAI, Pediatric Crohn's Disease Activity Index; SDS, SD score.

the mean (ie, a SDS of <-2), as an entry criterion. The median height velocity SDS was -3.35 , indicating extreme growth failure.

All the participants completed both parts of the study. The rhIGF-1 was generally well tolerated. Although subcutaneous rhIGF-1 has been associated with hypoglycaemia in children treated for GHIS, ${ }^{12}$ only one patient (LN01) had a single asymptomatic hypoglycaemic episode (blood sugar $<3.5 \mathrm{mmol} / \mathrm{l}$ ). This was corrected with oral glucose. This occurred following the $12 \mathrm{~h}$ dosage of rhIGF-1 during admission 2 in a child who had not eaten prior to the drug administration. No further episodes of hypoglycaemia occurred. There were no other adverse effects.

\section{Determinants of circulating IGF-1}

As previously demonstrated, children with Crohn's disease-induced growth failure had depressed circulating IGF-1 concentrations. The severity of disease in any one child varies over time, and this was reflected in the variation of IGF-1 between the first and second admissions, 3 or more months apart (figure 1A). Despite the variation both between and within patients, a single subcutaneous bolus of rhIGF-1 significantly increased IGF-1 in the circulation (figure 1). In some cases where the baseline IGF-1 was less depressed, the post IGF-1 level was increased to above normal (figure 1A). The concentrations of IGF-1 returned to baseline over the following $24 \mathrm{~h}$ (figure 1B).

IGF-1 is maintained in the circulation by IGF binding proteins, the most abundant being IGFBP- $3 .^{23} \mathrm{~A}$ major characteristic of Crohn's disease is protein-losing enteropathy, resulting in proteins being lost into the lumen of the intestine. ${ }^{24}{ }^{25}$ We aimed therefore to ascertain if the degree of protein-losing enteropathy(PLE) blunted the ability of subcutaneous rhIGF-1 to achieve significant peak concentrations, or if it directly affected IGF binding proteins. PLE was quantified by the concentrations of $\alpha 1$-antitrypsin in stool. ${ }^{26}$ Using this measure, PLE had no effect on the change in IGF-1 induced by a subcutaneous injection (figure 2A).

IGFBP-3 concentrations are depressed in children with chronic IGF-1 deficiency ${ }^{27}$ and all children in the study had low IGFBP-3 (figure 2B). We wished to determine, however, whether IGFBP-3 concentrations depended on the degree of PLE, as this would indicate that PLE may affect IGF-1 pharmacokinetics. However, no association was observed.

In the second admission, the participants received twice daily doses, to determine if IGF-1 concentrations would be enhanced over a longer period. The initial injection increased the IGF-1 concentrations into the normal range (figure 1A). Increases over a sustained period were successfully achieved (figure 1C) and as expected multiple daily dosing led to lower variability between peak and trough concentrations. Taking the area under the curve divided by time as the average IGF-1 concentration, it became clear that on $120 \mu \mathrm{g} / \mathrm{kg}$, some children had an average IGF-1 SDS of greater than +2.5 , while other children had appropriate concentrations. Increased circulating IGF-1 in acromegaly has been linked with an increased risk of colon cancer. ${ }^{13} 28$ Fortunately, we have a clear understanding of how IGF-1 concentrations relate to colon cancer risk in acromegaly. ${ }^{13}$ These studies show that the increased cancer risk was seen in individuals whose circulating IGF-1 was +2.5 SDS or greater. Using our data, we developed a model from which the dose-concentration relationship could 
Figure 1 Subcutaneous recombinant human IGF-1 (rhlGF-1) increases the circulating concentrations of insulin-like growth factor-1 (IGF-1) in children with growth failure induced by Crohn's disease. (A) IGF-1 SD scores (SDS) below the normal range in both first (mean -1.78 (SD 1.37)) and second admissions (mean -2.34 (SD $0.75)$ ) are significantly increased a single injection of rhIGF1 $(p<0.0005$ and $<0.0001$, respectively). (B) An injection reaches a peak within $4 \mathrm{~h}$ and returns to low levels within $24 \mathrm{~h}$. (C) Twice daily injections of rhIGF-1 increase circulating IGF-1 over a sustained period. rhIGF-1 was given on day 1 and the circulating concentrations allowed to fall, before giving twice daily injections on days 4 and 5 .
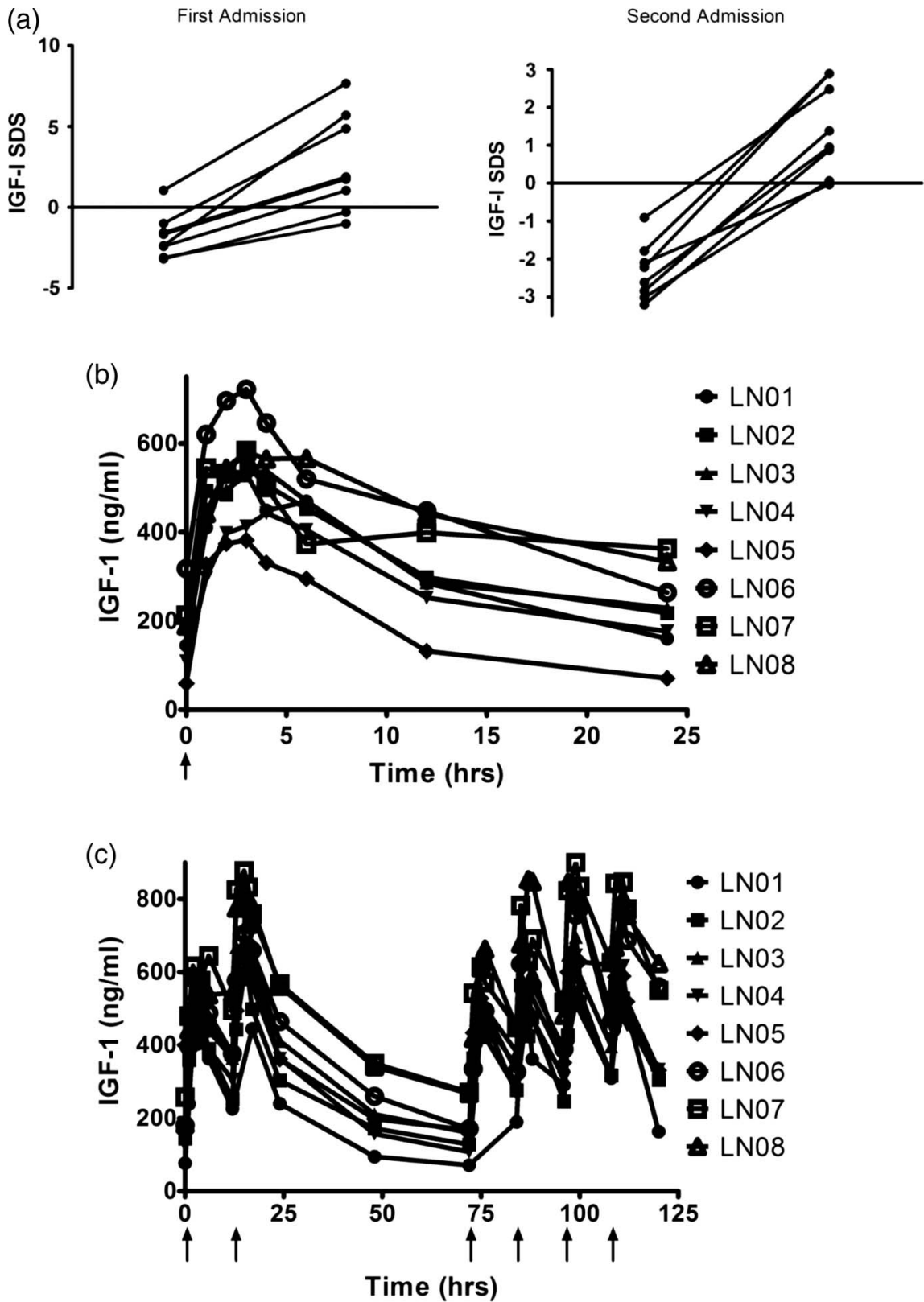

be derived. We then investigated the covariates on which dosing could be individualised. This allowed us to correct circulating IGF-1 without causing excessively high concentrations: ensuring that our dosing regimens resulted in concentrations that were below +2.5 SDS, we developed a utility model to predict the IGF-1 SDS achieved on regular dosing.

\section{Mathematical modelling of IGF-1 links endogenous} production to disease severity

A turnover model which accounted for both endogenous production and exogenous dosing of IGF-1 was fitted to the data (see methods for mathematical formulae) using non-linear mixed effects analysis. Four fixed effects were estimated, namely endogenous synthesis rate $\left(\mathrm{K}_{\mathrm{SYN}}\right)$, exogenous absorption rate through the skin following subcutaneous injection $\left(\mathrm{K}_{\mathrm{a}}\right)$, systemic clearance $\left(\mathrm{C}_{\mathrm{L}}\right)$ and distribution volume $\mathrm{V}_{\mathrm{D}}$. Parameter level random effects (intersubject variability) were included on $\mathrm{K}_{\mathrm{SYN}}$ and $\mathrm{C}_{\mathrm{L}}$ (table 2). A further level of random effects (interoccasion variability) also provided significantly improved fit when added to $\mathrm{K}_{\mathrm{SYN}}$. Following a limited covariate analysis, the PCDAI score was found to significantly improve fit when added to $\mathrm{K}_{\mathrm{SYN}}$, with $\mathrm{K}_{\mathrm{SYN}}$ falling with increasing disease severity (figure 3A). The effect of disease severity as measured by PCDAI was tested for $\mathrm{C}_{\mathrm{L}}$ and $\mathrm{K}_{\mathrm{SYN}}$ with significant improvement $(\mathrm{p}<0.001)$ being shown for $\mathrm{K}_{\mathrm{SYN}}$. Furthermore, adding the PCDAI score as a covariate to $\mathrm{K}_{\mathrm{SYN}}$ allowed interoccasion variability to be removed without detriment to the model fit (no change in log-likelihood). Adding PCDAI to $\mathrm{K}_{\mathrm{SYN}}$ also decreased interindividual variability. In short, disease severity was a major driver of IGF-1 synthesis rate both between patients and in the same patient on different occasions. 

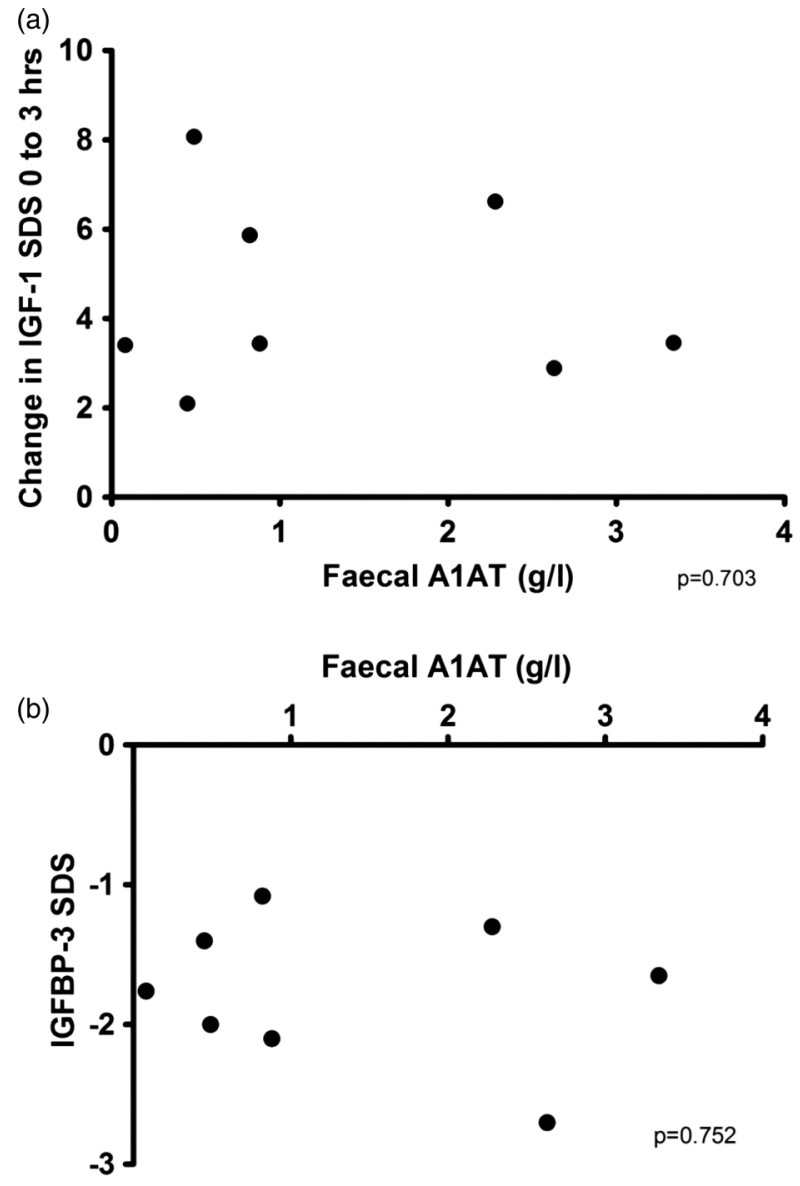

Figure 2 Protein-losing enteropathy did not alter insulin-like growth factor-1 (IGF-1) or IGFBP-3. (A) Variations in protein-losing enteropathy (as measured by faecal $\alpha 1$-antitrypsin) did not correlate with changes in IGF-1 concentrations achieved on giving recombinant human IGF-1 $(p=0.703)$. (B) Variations in protein-losing enteropathy did not correlate with IGFBP-3 concentrations.

There was good agreement between model predictions and observed concentrations (figure 3B), and trendless distribution of standardised residuals, indicating that the parametric modelling assumptions were satisfied (figure $3 \mathrm{C}-\mathrm{E}$ ). The median of the simulated data was not significantly different to the median of the observed data (figure 3F). Superimposing model predictions at a population level and individual level on the observed data showed that model predictions captured the dynamic behaviour of the system (figure 4).

\section{Dosing to maintain circulating rhIGF-1 concentrations in the target range}

We undertook mathematical modelling to quantify the relationship between endogenous IGF-1 production and exogenous dosing, and to understand how IGF-1 average concentrations (area under the curve/time) can be adjusted. Using the knowledge that in acromegaly there is no increased risk of cancer in patients whose IGF-1 is below $+2.5 \mathrm{SDS},{ }^{13}$ we defined the optimal IGF-1 concentration range as being between 0 and +2.0 SDS. This range would improve growth without elevating cancer risk. Different possible dose scaling systems were then explored to maximise the probability of an individual having IGF-1 levels in the target range. By individualising dose by weight, age (because different aged children have different target circulating IGF-1 levels) and PCDAI score, $92.7 \%$ of children were predicted to be corrected to less than or equal to +2.0 SDS $(95.3 \%$ below +2.5 SDS; figure 5). We can therefore suggest a dosing scheme that limits the risk of malignancy to that of the normal patient population. The dosing schedule recommended from the utility function is age 10 to $<12$ years, $21 \mu \mathrm{g} / \mathrm{kg}$ plus $1 \mu \mathrm{g} / \mathrm{kg} /$ PCDAI point; age 12 to $<14$ years, $41 \mu \mathrm{g} / \mathrm{kg}$ plus $1.4 \mu \mathrm{g} / \mathrm{kg} /$ PCDAI point.

\section{DISCUSSION}

Impaired growth has been a recognised feature of children with Crohn's disease for 50 years. ${ }^{29}$ In 1986, low IGF-1 was associated with poor growth in these children $^{30}$; over the following decade, it was realised that the depressed concentration was a direct consequence of inflammation, ${ }^{8} 10$ and not merely the result of poor energy intake or undernutrition. The best strategy to increase IGF-1 and therefore to improve growth is the resolution of inflammation. Treatments which reverse the inflammation, but do not actively suppress growth,

Table 2 Parameter estimates from the model including non-parametric $95 \% \mathrm{Cl}$ from a bootstrap of 714 successful runs

\begin{tabular}{|c|c|c|c|c|}
\hline Parameter & Estimate & Bootstrap median & $\begin{array}{l}\text { Bootstrap } \\
\text { 2.5th percentile }\end{array}$ & $\begin{array}{l}\text { Bootstrap } \\
\text { 97.5th percentile }\end{array}$ \\
\hline $\mathrm{C}_{\mathrm{L}}(\mathrm{l} / \mathrm{h} / 70 \mathrm{~kg})$ & 1.61 & 1.60 & 1.36 & 1.82 \\
\hline$V_{D}(1 / 70 \mathrm{~kg})$ & 2.42 & 2.41 & 1.78 & 3.10 \\
\hline $\mathrm{K}_{\mathrm{SYN}}(\mu \mathrm{g} / \mathrm{h})$ & 433 & 423 & 352 & 490 \\
\hline $\mathrm{Ka}\left(\mathrm{h}^{-1}\right)$ & 0.10 & 0.10 & 0.083 & 0.12 \\
\hline Coefficient of PCDAI on $\mathrm{K}_{\mathrm{SYN}}$ & -6.57 & -6.41 & -8.19 & -4.89 \\
\hline IIV on CL (\%CV) & 10.38 & 9.46 & 3.49 & 15.1 \\
\hline IIV on $\mathrm{K}_{\mathrm{SYN}}(\% \mathrm{CV})$ & 24.61 & 24.10 & 9.98 & 33.58 \\
\hline Residual error proportional (\%CV) & 9.81 & 9.69 & 7.85 & 11.04 \\
\hline Residual error, additive $(\mu \mathrm{g} / \mathrm{l})$ & 28.32 & 25.93 & 13.29 & 42.78 \\
\hline
\end{tabular}



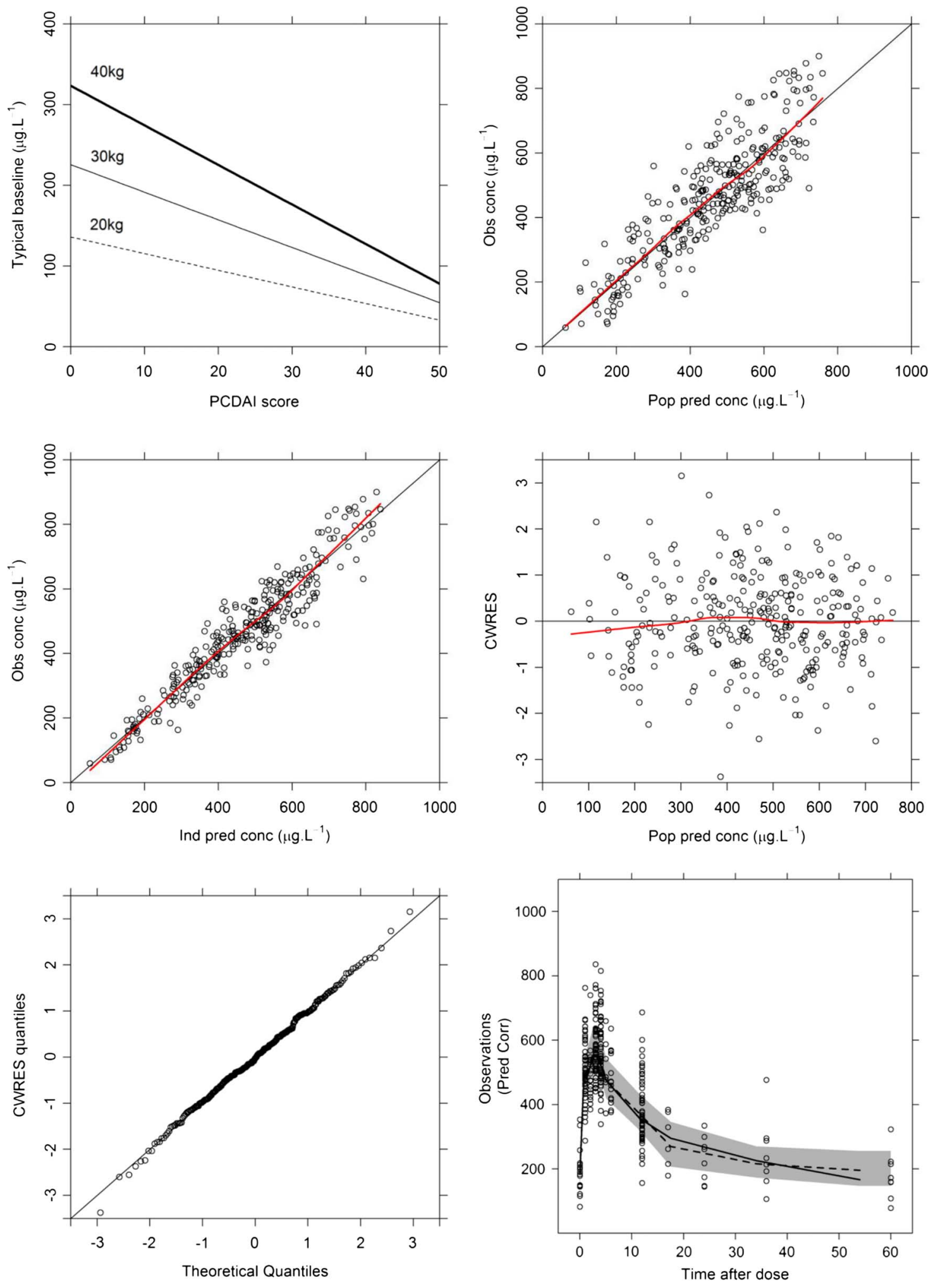

Figure 3 Insulin-like growth factor-1 (IGF-1) in a mathematical model. (A) Increasing disease activity (Pediatric Crohn's Disease Activity Index) significantly $(\mathrm{p}<0.001)$ diminishes the estimates of $\mathrm{K}_{\mathrm{syn}}$ in the covariate model building. (B) Population model predictions versus observed concentrations are unbiased, indicating good structural model fit. (C) Individual model predicted concentrations are in agreement with observed concentrations. (D) Conditional weighted residuals (CWRES), which are a form of standardised residuals expected to follow the Normal Independent Distribution (NID; 0,1 ) lie within -2 and +2 SDs and do not change with model predictions, indicating good structural model fit. (E) Similarly, the QQ plot of CWRES indicate that the assumption of normality of residuals is met; (F) Median observed IGF-1 concentrations (solid line) similar to median simulated (dashed line) and observed median lies within $95 \% \mathrm{Cl}$ of the model simulations (grey-shaded area). 
Figure 4 Population level (blue line) and individual (red line) model predictions are similar to observed data (black open circles) in both (A) single dose and $(B)$ repeated doses in each part of the study.
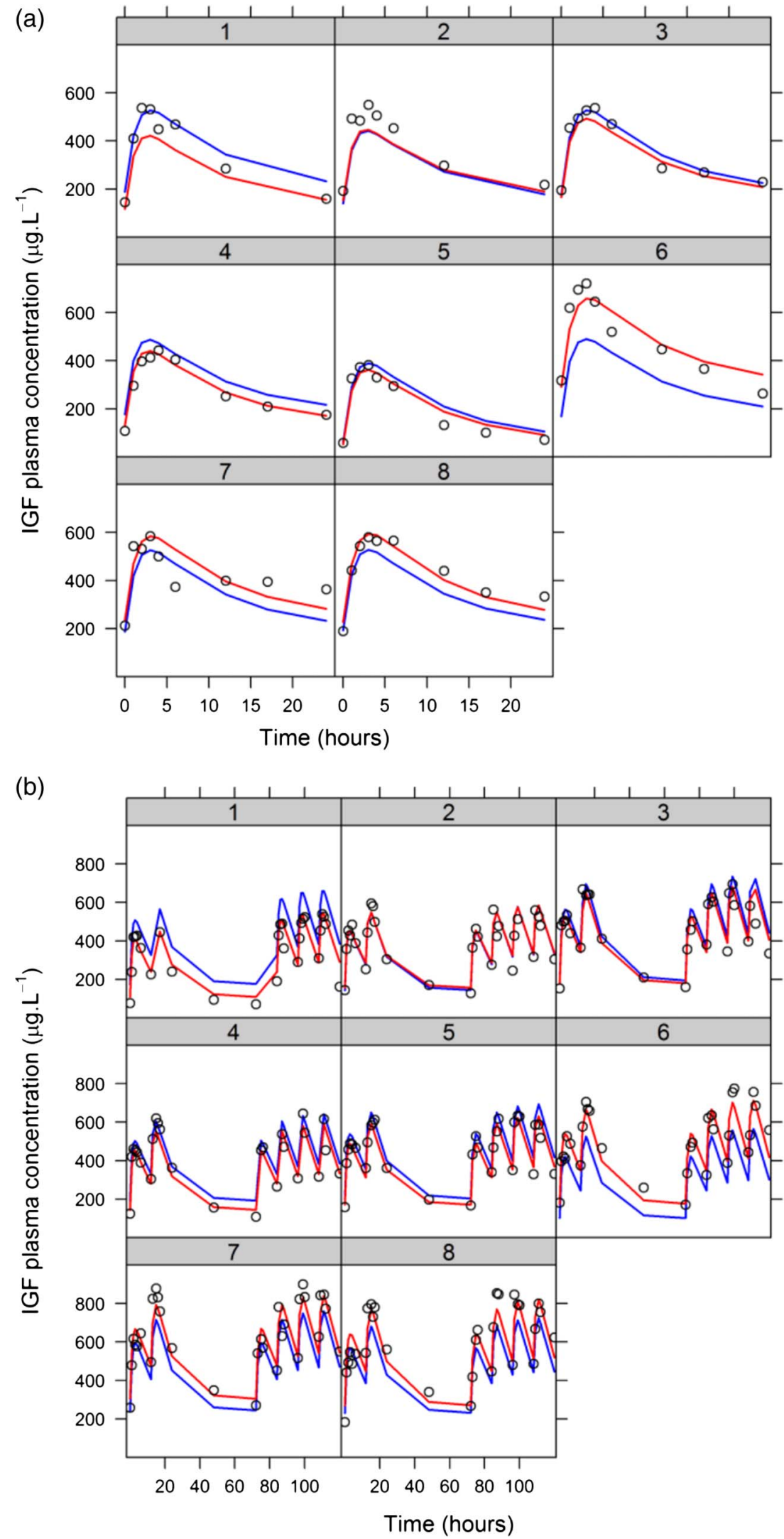

such as surgery, ${ }^{31}$ anti-TNF ${ }^{32} 33$ and enteral $\operatorname{diets}^{6}{ }^{34}$ have all been shown to improve linear growth.

Nevertheless, there are patients with Crohn's disease whose inflammation cannot be reversed. In this group, 


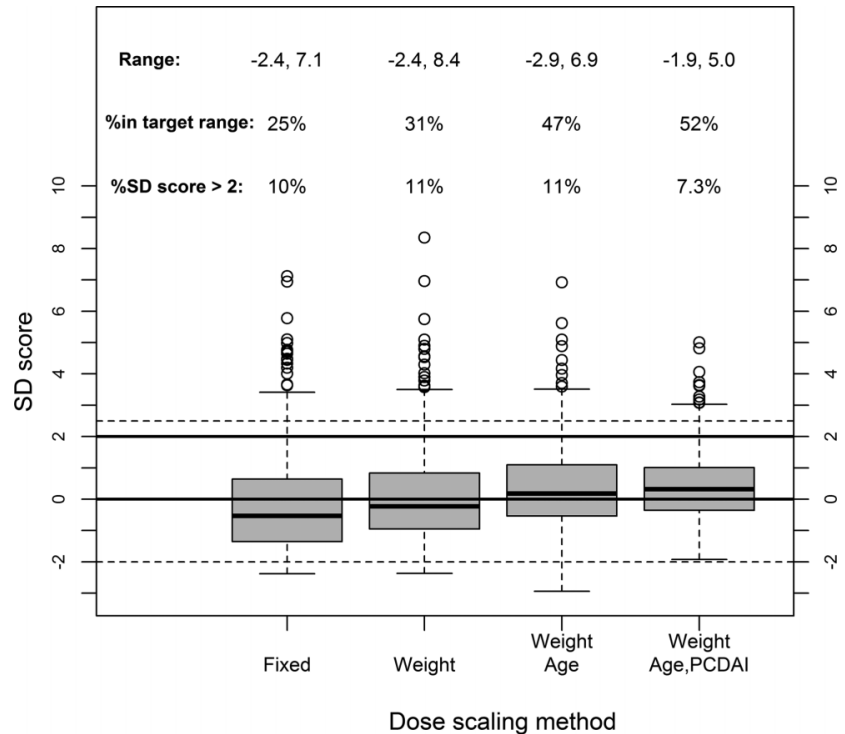

Figure 5 Incorporation of a disease activity index into dose calculations allows an accurate prediction of circulating insulin-like growth factor-1 (IGF-1). Utility function results showing the effect of increasing sophistication on dose scaling method. Scaling by weight, age group and Pediatric Crohn's Disease Activity Index score limits average IGF-1 concentrations in $93 \%$ of children to less than +2 SD score (SDS). Solid lines are the target range of 0 to +2 SDS, dashed lines are for reference -2 SDS and +2.5 SDS.

rhIGF-1 would be efficacious in improving IGF-1 concentrations, as it does in children with GHIS. However, there are significant problems in applying our knowledge of rhIGF-1 usage in GHIS to children with Crohn's disease. First, children present at a much later age in Crohn's disease than they do in GHIS, which is caused by a genetic mutation (approximately 8-15 years as opposed to less than 5 years old). The compartments of the IGF-1 system including several IGF binding proteins cannot be assumed to distribute as they do in younger children, particularly if the relative volumes of these compartments change at the time of puberty. Second, both IGF-1 and the IGF binding proteins are circulating proteins. Proteins are lost into the intestine through PLE, where inflammation reduces the ability of the intestinal vasculature to maintain them in the capillary lumen. ${ }^{37-39}$ The PLE could, in theory, alter the kinetics of IGF-1. Finally, very high and sustained circulating IGF-1 concentrations are associated with an increase in colon cancer in middle aged and older patients with acromegaly. A modelling approach to kinetics and dosing was necessary to avert causing high average IGF-1 concentrations.

The reduction in IGFBP-3 raises the question as to whether giving rhIGF-1 to children with a reduced IGFBP-3 may increase free IGF-1 concentrations. Since we did not have access to an assay for free IGF-1, our data are not totally informative on this issue. However, they will not have risen to unsafe levels from saturating the IGF-1 binding capacity. The concentrations of IGFBP-3 are not greatly depressed in the affected children. Even in the most severe case, the IGFBP-3 is within 2 SDs of normal. In addition, IGF-1 is over $95 \%$ bound to IGF binding proteins, with an excess of binding capacity. In general, when analysing pharmacokinetic data, the changes in protein binding do not affect free concentrations, but may affect free fraction. This means that for two individuals with the same total concentration, the free concentration maybe elevated in the one with lower binding protein. However, two individuals with different IGFBP-3 concentrations given rhIGF-1 will not achieve the same total concentrations because as IGF-1 undergoes first-order elimination, higher free concentrations will be more rapidly eliminated due to homeostasis. On analysing our small dataset, IGFBP-3 was not a significant covariate for the volume of distribution in our model. Indeed, our model predicts that the majority of patients will have total concentrations just above the normal range.

Several children enrolled in the study had delayed puberty (table 1). Although this is commonly observed in Crohn's disease, the study could be criticised for not taking this into account when calculating IGF-1 SDSs, as circulating IGF-1 increases in puberty. We do not have normative data for circulating IGF-1 against pubertal stage. However, delay in puberty is closely correlated with a delay in bone age, as measured on a wrist x-ray. We therefore recalculated each child's IGF-1 SDS against their bone age before and after the initial injection of rhIGF-1 (data not shown). However, this made little difference to the results obtained when comparing these data to those based on chronological age (figure 1A).

Previous studies on rhIGF-1 pharmacokinetics ${ }^{40} 41$ have mainly focused on its use in malnourished adult patients with renal failure, where it has been used to maintain protein balance. These reports undertook purely descriptive analyses such as area under the concentration-time curve and comparing healthy volunteer parameters with patients, rather than modelling the data. Furthermore, they did not account for endogenous IGF-1 production. If we were to use our data to recommend a dose, a more sophisticated approach was required. In this study, we fitted a structural model that simplified the system without losing the biological interpretation of the parameters. Mixed effects modelling allowed for the addition of interindividual and interoccasion variability in model parameters, in addition to residual variability. We were, therefore, able to simultaneously fit the model to all patients and investigate covariate-parameter relationships. Instead of exploring dose recommendations by simulation, we aimed to optimise the dose based on the target SDS and we minimised deviations from this using least-squares regression. ${ }^{42}$ The advantage of this approach, over testing competing dosing regimens by simulation, is that once the optimal target is defined, the optimal dose needed to reach that target is determined in a single step. Testing covariates 
for dose scaling is also simple with this method. Furthermore, by using a large dataset of hypothetical patients with real Crohn's Disease demographics, we were able to show how scaling dose by age, weight and PCDAI score could adequately and safely correct IGF-1 (figure 5).

The goodness-of-fit plots (figures 3B-E and f4) show that the model predictions are an unbiased description of the data and simulated data that are not significantly different to the observations (figure 3F). Furthermore, covariate analysis showed that the disease severity (PCDAI score) significantly reduced endogenous synthesis $\left(\mathrm{K}_{\mathrm{syn}}\right)$ rather than affecting IGF-1 clearance. Variations in IGF-1 synthesis distinguish patients with Crohn's disease from children with GHIS.

A possible criticism of using PCDAI to quantify disease in this context is that it includes growth as a marker of inflammation, and it could be suggested that the dependence of $\mathrm{K}_{\mathrm{syn}}$ on PCDAI might be due to the height velocity element of the index. Recently, the determinants of the disease activity index have been separately analysed for predictive value in defined populations of children with Crohn's disease. ${ }^{43}$ Linear growth was discovered not to be discriminatory. This report developed a new index, the weighted Pediatric Crohn's Disease Activity Index (wPCDAI), based on these observations, which does not include growth. We repeated our covariate modelling with wPCDAI and showed that adding it to $\mathrm{K}_{\text {syn }}$ reduced parameter variability and significantly improved model fit, in the same way as the standard PCDAI had. Thus, the relationship between $\mathrm{K}_{\mathrm{syn}}$ and disease activity was due to the objective measures of inflammation and not to the growth component of the PCDAI calculation.

This report focused on the effects of IGF-1. As aforementioned, hGH may also be of benefit on the linear growth of children with Crohn's disease. ${ }^{36}$ It was not the purpose of the present study to examine which therapy would be more efficacious; however, future studies comparing IGF-1 with hGH in a controlled randomised multicentre study are planned. This trial will also give us the opportunity to test the dosing regimen derived from this model presented in the present report on a wide sample of children.

Patients and their support groups have long requested more research into therapies that directly improve growth in children whose inflammation cannot be controlled. The present study shows that twice daily rhIGF-1 can enhance average circulating IGF-1 concentrations into the upper normal range. The use of a utility function from mathematical modelling allows paediatricians to give rhIGF-1 without their entering an unphysiological high range, hence reducing the increased risk of cancer.

\footnotetext{
Author affiliations

${ }^{1}$ Centre for Digestive Diseases, Blizard Institute, Barts and The London School of Medicine and Dentistry, Queen Mary, University of London, London, England, UK

${ }^{2}$ Infectious Diseases and Microbiology Unit, Institute of Child Health, University College London, London, England, UK
}

${ }^{3}$ Centre for Endocrinology, William Harvey Research Institute, Barts and The London School of Medicine and Dentistry, Queen Mary, University of London, London, England, UK

Acknowledgements We acknowledge the expertise of the paediatric gastroenterology and research nursing staff at Barts Health NHS Trust in this inpatient study.

Contributors IRS conceived the study and helped in its design; obtained the funding, ethics, MHRA approval and drafted initial manuscript; JFS developed the mathematical modelling; AVR consented the patients; arranged admission and undertook all the investigation; SK oversaw the clinical care of the patients while admitted for research investigation. MOS helped design the study and provided paediatric endocrinology expertise. All authors contributed to the final manuscript.

Funding The work was funded by a project grant from the Crohn's and Colitis Foundation of America (№. 1774). The IGF-1 was supplied free of charge by Ipsen UK, who also paid for the rhIGF-1 and IGFBP-3 measurements. The study was adopted by the Medicines for Children Research Network (MCRN) of the National Institute of Health Research and accredited by the UK Clinical Research Network (UKCRN). JFS received funding from a UK Medical Research Council Fellowship (grant number G1002305).

Competing interests None.

Ethics approval East London Research Ethics Committee; MHRA.

Provenance and peer review Not commissioned; externally peer reviewed.

Data sharing statement Anomymised original data will be given to research academics at recognised university departments in line with the policies of Queen Mary, University of London. Requests should be made to Professor Sanderson. However, there are no data in addition to those published except as the individual numerical results that are displayed as figures. Patient identifiable data cannot be shared, as this is a condition of the research ethics committee approval.

\section{REFERENCES}

1. Sawczenko A, Sandhu BK, Logan RF, et al. Prospective survey of childhood inflammatory bowel disease in the British Isles. Lancet 2001;357:1093-4.

2. Lowe AM, Roy O, B-Poulin M, et al. Epidemiology of Crohn's disease in Quebec, Canada. Inflamm Bowel Dis 2009;15:429-35.

3. Henderson P, Hansen R, Cameron FL, et al. Rising incidence of pediatric inflammatory bowel disease in Scotland. Inflamm Bowel Dis 2012;18:999-1005.

4. Shamir R, Phillip M, Levine A. Growth retardation in pediatric Crohn's disease: pathogenesis and interventions. Inflamm Bowel Dis 2007;13:620-8.

5. Thomas MJ. The molecular basis of growth hormone action. Growth Horm IGF Res 1998;8:3-11.

6. Thomas AG, Holly JM, Taylor F, et al. Insulin like growth factor-I, insulin like growth factor binding protein-1, and insulin in childhood Crohn's disease. Gut 1993;34:944-7.

7. Bannerjee $\mathrm{K}$, Camacho-Hübner $\mathrm{C}$, Babinska $\mathrm{K}$, et al. Anti-inflammatory and growth-stimulating effects precede nutritional restitution during enteral feeding in Crohn disease. $J$ Pediatr Gastroenterol Nutr 2004;38:270-5.

8. Ballinger $\mathrm{AB}, \mathrm{Azooz} \mathrm{O}$, El-Haj T, et al. Growth failure occurs through a decrease in insulin-like growth factor 1 which is independent of undernutrition in a rat model of colitis. Gut 2000;46:694-700.

9. Sawczenko A, Azooz O, Paraszczuk J, et al. Intestinal inflammation-induced growth retardation acts through IL- 6 in rats and depends on the-174 IL-6 G/C polymorphism in children. Proc Natl Acad Sci U S A 2005;102:13260-5.

10. De Benedetti F, Alonzi T, Moretta A, et al. Interleukin 6 causes growth impairment in transgenic mice through a decrease in insulin-like growth factor-I. A model for stunted growth in children with chronic inflammation. J Clin Invest 1997;99:643-50.

11. Denson LA, Held MA, Menon RK, et al. Interleukin-6 inhibits hepatic growth hormone signaling via upregulation of Cis and Socs-3. Am J Physiol Gastrointest Liver Physiol 2003;284:G646-54.

12. Chernausek SD, Backeljauw PF, Frane J, et al. Long-term treatment with recombinant insulin-like growth factor (IGF)-I in children with 
severe IGF-I deficiency due to growth hormone insensitivity. J Clin Endocrinol Metab 2007;92:902-10.

13. Jenkins PJ, Frajese V, Jones AM, et al. Insulin-like growth factor and the development of colorectal neoplasia in acromegaly. J Clin Endocrinol Metab 2000;85:3218-21.

14. Inflammatory bowel disease in children and adolescents: recommendations for diagnosis- the Porto criteria. J Pediatr Gastroenterol Nutr 2005;41:1-7.

15. Hyams JS, Ferry GD, Mandel FS, et al. Development and validation of a pediatric Crohn's disease activity index. J Pediatr Gastroenterol Nutr 1991;12:439-47.

16. Hyams J, Ferry GD, Mandel FS, et al. Evaluation of the pediatric crohn disease activity index: a prospective multicenter experience. J Pediatr Gastroenterol Nutr 2005;41:416-21.

17. Beal S, Steven LB, Boeckmann A, et al. NONMEM. Ellicott City, MD: Icon Development Solutions, 1989-2009.

18. Anderson BJ, Holford $\mathrm{NH}$. Mechanism-based concepts of size and maturity in pharmacokinetics. Annu Rev Pharmacol Toxicol 2008;48:303-32.

19. Efron B. Bootstrap methods: another look at the jackknife. Ann Stat 1979;7:1-26.

20. Newby EA, Sawczenko A, Thomas AG, et al. Interventions for growth failure in childhood Crohn's disease. Cochrane Database Syst Rev 2005(3):CD003873.

21. Sawczenko A, Ballinger AB, Croft NM, et al. Adult height in patients with early onset of Crohn's disease. Gut 2003;52:454-5; author reply 455.

22. Pfefferkorn M, Burke G, Griffiths A, et al. Growth abnormalities persist in newly diagnosed children with Crohn disease despite current treatment paradigms. J Pediatr Gastroenterol Nutr 2009;48:168-74.

23. Le Roith D. Seminars in medicine of the Beth Israel Deaconess Medical Center. Insulin-like growth factors. N Engl J Med 1997;336:633-40.

24. Beeken WL, Busch HJ, Sylwester DL. Intestinal protein loss in Crohn's disease. Gastroenterology 1972;62:207-15.

25. Ferrante M, Penninckx F, De Hertogh G, et al. Protein-losing enteropathy in Crohn's disease. Acta Gastroenterol Belg 2006;69:384-9.

26. Karbach U, Ewe K, Bodenstein $\mathrm{H}$. Alpha 1-antitrypsin, a reliable endogenous marker for intestinal protein loss and its application in patients with Crohn's disease. Gut 1983;24:718-23.

27. Savage MO, Blum WF, Ranke MB, et al. Clinical features and endocrine status in patients with growth hormone insensitivity (Laron syndrome). J Clin Endocrinol Metab 1993;77:1465-71.

28. Jenkins PJ. Acromegaly and colon cancer. Growth Horm IGF Res 2000;10(Suppl A):S35-6.
29. Sobel EH, Silverman FN, Lee CM Jr. Chronic regional enteritis and growth retardation. Am J Dis Child 1962;103:569-76.

30. Kirschner BS, Sutton MM. Somatomedin-C levels in growth-impaired children and adolescents with chronic inflammatory bowel disease. Gastroenterology 1986;91:830-6.

31. Lipson AB, Savage MO, Davies PS, et al. Acceleration of linear growth following intestinal resection for Crohn disease. Eur J Pediatr 1990;149:687-90.

32. Borrelli O, Bascietto C, Viola F, et al. Infliximab heals intestinal inflammatory lesions and restores growth in children with Crohn's disease. Dig Liver Dis 2004;36:342-7.

33. Walters TD, Gilman AR, Griffiths AM. Linear growth improves during infliximab therapy in children with chronically active severe Crohn's disease. Inflamm Bowel Dis 2007;13:424-30.

34. Sanderson IR, Boulton P, Menzies I, et al. Remission induced by an elemental diet in small bowel Crohn's disease. Arch Dis Child 1987;62:123-7.

35. Heyman MB, Garnett EA, Wojcicki J, et al. Growth hormone treatment for growth failure in pediatric patients with Crohn's disease. J Pediatr 2008;153:651-8, 658 e1-3.

36. Denson LA, Kim MO, Bezold R, et al. A randomized controlled tria of growth hormone in active pediatric Crohn disease. J Pediatr Gastroenterol Nutr 51:130-9.

37. Sanderson IR, Udeen S, Davies PS, et al. Improvement of abnormal lactulose/rhamnose permeability in active Crohn's disease of the small bowel by an elemental diet. Gut 1987;28:1073-6.

38. Teahon K, Smethurst P, Levi AJ, et al. Intestinal permeability in patients with Crohn's disease and their first degree relatives. Gut 1992;33:320-3.

39. Fries W, Muja C, Crisafulli C, et al. Dynamics of enterocyte tight junctions: effect of experimental colitis and two different anti-TNF strategies. Am J Physiol Gastrointest Liver Physiol 2008;294: G938-47.

40. Rabkin R, Fervenza FC, Maidment $\mathrm{H}$, et al. Pharmacokinetics of insulin-like growth factor-1 in advanced chronic renal failure. Kidney Int 1996;49:1134-40.

41. Fouque D, Peng SC, Kopple JD. Pharmacokinetics of recombinant human insulin-like growth factor-1 in dialysis patients. Kidney Int 1995;47:869-75.

42. Jonsson S, Karlsson MO. A rational approach for selection of optimal covariate-based dosing strategies. Clin Pharmacol Ther 2003;73:7-19.

43. Turner D, Griffiths AM, Walters TD, et al. Mathematical weighting of the pediatric Crohn's disease activity index (PCDAI) and comparison with its other short versions. Inflamm Bowel Dis 18:55-62. 